\title{
THE INTERACTION EFFECTS OF TOP MANAGEMENT TEAM ATTRIBUTES AND ENVIRONMENT ON ORGANIZATIONAL GROWTH
}

Sisisin . Hal: $1-20$

\author{
D. Agus Harjito \\ Fakultas Ekonomi Universitas Islam Indonesia \\ Zunaidah Sulong \\ Department of Accounting, Universiti Putra Malaysia
}

\begin{abstract}
This paper attempts to explore how TMT (Top Management Team) attributes interact with environment dimensions to influence organizational growth. Specifically, this study will examine environmental dimensions as a potentially important moderator of the association between TMT attributes and organizational growth. However, the overall findings provide mixed results for the hypotheses tested. The results of direct effect show that: (1) organizational growth exhibits a significant positive relationship with TMT tenure; (2) TMT functional heterogeneity is insignificant with no change in the variance of organizational growth; and (3) positive but insignificant relationship between industrial heterogeneity and organizational growth. Furthermore, the interaction effect results indicate that: (1) as munificence increases, the relationship between TMT tenure and organizational growth shows increasingly positive; (2) concentration, dynamism and munificence moderate the relationship between TMT functional heterogeneity and organizational growth; (3) finally, the interaction effect also provide mixed results, such: as environment concentration increases, the relationship between TMT industrial heterogeneity and organizational growth increases positively; by contrast, as environment dynamism increases, the relationship between TMT industrial heterogeneity and organizational growth increases negatively; while the interaction between TMT industrial heterogeneity and environment munificence is not significant to explain the organizational growth.
\end{abstract}

Key words: Organization growth, environment, management team.

\section{INTRODUCTION}

Organizational growth can potentially provide the organizational business a myriad of benefits, including greater efficiencies through economies of scale, increased power, the ability to withstand environmental change, increased survival rates, increased profits, and increased prestige for organizational members. Consequently, organizational growth is often used as an indicator of effectiveness for organizational performance and is a fundamental concern of many practicing managers (Weinzimmer 1997). According to Hubbard and Bromiley's (1995), organizational growth is the most commonly identified measure of overall organizational performance (cited in Dess 1987; Johnson \& Thomas 1987; Hamilton \& Shergill 1992; Weinzimmer et al. 1998). Therefore, this study will use organizational growth as a measure of organizational performance because the concern is more on the effectiveness than the efficiency perspective (Dess \& Origer 1987). 
It is also widely acknowledged that an effective top management team (henceforth TMT) is critical to the success of its organization (Hambrick \& Mason 1984). Despite the extensive literature on TMT attributes, disagreement persists as to whether specific aspects of TMT have positive or negative results on organizational performance. Heterogeneous backgrounds of TMT are thought to improve decision quality by insuring that a wide variety of skills, knowledge, abilities and perspectives are brought to bear on the strategic decision under consideration. However, there are researchers have proposed that an effective TMT should be comprised of individuals from different backgrounds (e.g., Bantel \& Jackson 1989). Hambrick \& Cho (1996) refer to TMT heterogeneity as a "double-edged sword", as a "mixed bag" of empirical evidence, indicating that heterogeneous teams have both beneficial and detrimental effects on organizational outcomes.

Moreover, environmental influences on organizations and TMT have been well documented in the industrial organization and organization theory literatures. Several scholars have made theoretical approaches to understanding the environment's effect on organizations; that include task/decision uncertainty, environmental conditions and perceived uncertainty, the environment as a source of resources, and as a source of variation in organizational forms (cited in Sharfman \& Dean 1991). More recently, organizational researchers have proposed that understanding the relationship between TMT heterogeneity and outcomes lies in identifying relevant contingency and/or moderating variables that allow for more complex types of effects (Hambrick \& Mason 1984). Therefore, research on organizational environments has been characterized by a multiplicity of approaches. This diversity can be viewed as strength in the sense that different perspectives provide alternative and richer insights than would have been possible if uniform perspectives are adopted (Dess \& Rasheed 1991).

In this study, such an approach will be pursued that goes beyond Hambrick \& Mason (1984) by examining environmental dimensions as a potentially important moderator of the association between TMT attributes and organizational growth. Following part of the approach by Weinzimmer et al. (1998) this study takes a moderate stance as it investigates the direct effects between TMT attributes and organizational growth, jointly with the interaction effects of the environmental dimensions. Specifically, this study attempts to propose that environmental dimensions moderate the relationship between TMT attributes and organizational growth.

The remainder of this paper is organized as follows. Section II reviews the literature of the linkage between TMT attributes and organizational growth, and the moderating role of environmental dimensions. Further, this section explains the hypotheses development, that includes direct 
and interaction effects. Section III discusses the methodology employed, while Section IV presents and discusses the results. Finally, Section V provides the conclusions and implications of the study.

\section{LITERATURE REVIEW AND HYPOTHESES DEVELOPMENT}

\section{Direct Effects}

There is no single characteristic of TMT that has been studied sufficiently to understand its complete effects on firm performance. The available literature argue that a TMT's tenure in the organization affects (and serves as an approximation for) the team's commitment to the status quo, its informational diversity, and its attitudes toward risk (Finkelstein \& Hambrick 1990). In turn, TMT tenure is expected to affect firm performance. Specifically, firms led by long-tenured executives will tend to have (1) persistent, unchanging strategies; (2) strategies that conform closely to industry averages; and (3) performance that conforms to industry averages (Finkelstein \& Hambrick 1990).

Tenure tends to restrict information processing. Over time, organization members develop habits, establish "customary" information sources, and rely more and more on past experience instead of on new stimuli (Katz 1982) (cited in Finkelstein \& Hambrick 1990). With organizational tenure, managers tend to develop a particular repertoire of responses to environmental and organizational stimuli that acts against any change in policy (Miller 1991). As cited in Keck (1997), variation in team tenure has been found to be related inversely to several categories of outcomes. Higher levels of variation in tenure are associated with lower levels of: (1) communication with the outside and information dissemination; (2) commitment to group goals and norms; (3) socialization; (4) justification of past actions; and (5) team performance.

Several scholars have made related arguments, typically in the context of executive succession (Romanelli 1989). For example, Miller and Friesen (1984) have argued that long-serving CEOs often show politically and emotionally motivated resistance to change. The effect of long tenures is to reduce the adoption of novel or unique strategies (Katz 1982) (cited in Finkelstein \& Hambrick 1990), thus bringing the organization into general conformity with industry tendencies. Teams with short tenures have fresh, diverse information and are willing to take risks, often departing widely from industry conventions. Short-tenured TMT who undertake deviant strategies may experience very high or very low performance within the industry. As tenure increases, perceptions become very restricted and risk taking is avoided. The lowest-risk thing to do is to follow the general tendency of mainstream competitors. Thus, even though change is expected to diminish 
as tenures increase, as whatever strategic change does occur to bring the firm into closer conformity with industry averages. Long-tenured TMT make few strategic changes, and those few are merely imitative, reflecting impoverished information processing and risk aversion.

Although TMT tenure has a very clear effect on organizational outcomes, firm strategy and performance may influence the distribution of tenures at the top as well. For example, firms following persistent strategies may make few changes in TMT composition, increasing tenures. The hypotheses that have generated from the above discussion do not explicitly consider reverse causality in modeling the effects of TMT tenure on firm performance.

Newly formed teams may take up to six months to become productive (Gabarro 1987) (cited in Keck 1997). The team may be unproductive while its members learn interaction patterns and roles, develop cohesion, and absorb the information they need to perform the task (Keck 1997). As cited in Keck (1997), if team members remain together for long periods, they begin to decrease communication with the outside and to filter outside information that may be potentially disruptive but beneficial to successful performance. Cohesion and communication among members may remain high, but scanning activities decline. Priem (1990) conceptualize those trends as a curvilinear relationship between top team characteristics and organizational outcomes.

Shorter-tenured, heterogeneous teams are found to provide the skill needed to address environmental complexities and will be more productive in turbulent environments because they deliver problem solving skills and new perspectives on strategic formulation and implementation processes. Longer-tenured, homogeneous teams are found to be more productive in stable environments because they will promote basic team maintenance functions (socialization, cohesion, etc.). Firms that are the most successful financially are ones that match their team structures to the environmental context (Keck 1997).

Numerous studies have found significant associations between the demographic composition of the TMT and organizational characteristics. Studies have documented the tendency for young, short-tenure, highly educated teams to be relatively innovative, even after controlling for the type of industry (Bantel \& Jackson 1989). Organizational tenure of TMT members is found to be strongly associated with strategic persistence, or absence of change (Finkelstein \& Hambrick 1990). Other studies have found organizational effects arising from industry experience (Eisenhardt \& Schoonhoven, 1990).

TMT with long organizational tenure are expected to have great social cohesion, lessening the likelihood that individual members of a team 
will challenge the status quo (Michel \& Hambrick 1992). Long tenure provides a better understanding or organizational policies and procedures (Hambrick \& Mason 1984). The length of time a TMT has been in the job may have a vital effect on the likelihood that he or she will effectively use of the diverse knowledge and skills. Bantel \& Jackson (1989) show that teams with longer organizational tenures exhibited a greater commitment to the status quo and to the culture and norms of their organizations. Another relevant TMT characteristic is TMT age heterogeneity. An empirical evidence by Richard \& Shelor (2002) show that TMT age heterogeneity has a significant relationship with organizational growth. In addition, longer TMT tenure has a clearer effect on organizational outcomes and firm strategy, and thus increased organizational growth.

H1 : Organizations with longer-tenured TMT will exhibit higher organizational growth than those with shorter-tenured TMT.

The upper-echelons perspective, as set forth by Hambrick and Mason (1984) (cited in Finkelstein \& Hambrick 1990), attributes major influence to a firm's leaders. Organizational outcomes, such as strategies and performance, are expected to reflect the characteristics of these leaders. This "upper-echelons theory" is based on the premise that top managers structure decision situations to fit their view of the world. As a result, a central requirement for understanding organizational behavior is to identify those factors that direct or orient executive attention. An important feature of Hambrick and Mason's (1984) upper-echelons perspective, which are adopted here, is a primary focus on the TMT rather than strictly on the chief executive. The limited empirical evidence on whether the top person or the broader team is a better predictor of organizational outcomes consistently supports the conclusion that the full team has greater effect (e.g. Bantel \& Jackson 1989; Finkelstein \& Hamrick 1990; Haleblian \& Finkelstein 1993).

Taking the upper-echelons perspective, this paper examines the effects of TMTs heterogeneity on organizational growth. The heterogeneity variables, a central construct in the literature on top management, are expected to be important in competitive decision-making, conferring breadth of perspective, on one hand, but with the potential for team dissensus and inefficiency, on the other hand (Jackson 1992).

Researchers have found inconsistent evidence about the effects of TMTs heterogeneity on organizational performance: positive effects (Eisenhardt \& Schoonhoven 1990), negative effects (Murray 1989), and no effects (Michel and Hambrick 1992). It is clear from the available literatures that heterogeneity may be a double-edged sword. On the other hand, heterogeneity is expected to reduce the firm's speed, both in acting and responding, possibly leading to lower performance (Eisenhardt \& Schoonhoven 1990). 
Several authors have discussed and/or shown the effects of teammember heterogeneity on team and firm performance (Hambrick \& Mason 1984; Bantel \& Jackson 1989; Murray 1989). For example, functional heterogeneity among bank executives increased innovations in service offerings (Bantel \& Jackson 1989). These relationships may occur because increased environmental scanning, generation of alternatives, and multiple interpretations of information (Hambrick \& Mason 1984), all of which are related to the task functions of the team.

Scholars of top teams have become particularly interested in the effects of the team's heterogeneity, the variation in team members' characteristics, which has been called a theoretical fulcrum for research on groups and TMT (Jackson 1992). Although many investigations have been conducted on the effects of heterogeneity in groups in general (reviewed by Jackson 1992). Bantel \& Jackson (1989) found that TMT heterogeneity in educational level and functional background is positively associated with innovativeness in a large sample of banks. Eisenhardt \& Schoonhoven (1990) show that growth rates of semiconductor companies are positively related to the top team's heterogeneity in industry tenure.

Other studies have found negative effects from TMT heterogeneity. O'Reilly and Flatt (1989) (cited in Hambrick \& Cho 1996) show that company innovation is negatively related to team heterogeneity in firm tenure in a wide cross section of firms. O'Reilly, Snyder, and Boothe (1993) (also cited in Hambrick \& Cho 1996) similarly find that team heterogeneity in firm tenure is negatively related to adaptive change in a sample of electronics firms.

Michie et al. (2002) examine the relationship between TMT heterogeneity and performance. The results indicate that when consensus on organization wide goals is high among functionally heterogeneous TMT members, they are more likely to collaborate and improve the quality of their decisions. These findings may help to explain the equivocal results of previous research attempts to link TMT heterogeneity to successful performance outcomes.

The results from Hambrick \& Cho (1996) indicate that TMTs heterogeneity may have potential benefits and drawbacks to the firm's competitive behaviors. It is understandable, then, that prior research has produced mixed results on the influence of TMT heterogeneity on overall organizational performance.

The literature cited supports that conclusion that heterogeneity is related positively to successful outcomes by widening scanning activities and varying alternatives, thereby improving problem-solving activities. A team composed of members with different backgrounds will scan the environment more broadly and will make the solution set broader and more 
complex. A heterogeneous team will have varied skill needed to address complexities of the environment. Consequently, problem-solving functions improve and outcomes will be more successful.

In a study of top management team heterogeneity, Bantel \& Jackson (1989) and Richard \& Shelor (2002) all find that TMTs with diverse capabilities produce more innovative and higher quality decisions than teams with less diverse qualities. Teams composed of members with diverse backgrounds and characteristics produce a wider variety of ideas, alternatives and solutions than teams composed of people with similar demographic characteristics (Jackson 1992). Similarly, heterogeneity in tenure increases the chance that a TMT will break with past patterns and practices, and will attempt to reconfigure an organization's strategy (Boeker 1997). The hypotheses concerning TMT heterogeneity and firm performance are thus:

H2a : Organizations with high level of functional heterogeneity of TMT will exhibit higher organizational growth than those with low level of functional heterogeneity of TMT.

$\mathrm{H} 2 \mathrm{~b}$ : Organizations with high level of industrial heterogeneity of TMT will exhibit higher organizational growth than those with low level of industrial heterogeneity of TMT.

\section{Interaction Effects}

Environmental influences on organizations and the theoretical relationship between organizational environment and growth have been well documented in the organization theory literature. Environmental factors pertain to heterogeneity in and range of environmental complexity (Richard \& Shelor 2002). According to Weinzimmer \& Nystrom (1998), there are three environmental dimensions, which include dynamism, munificence and concentration. The first dimension is dynamism that represents the instability with respect to occurrence of exceptional events in the environment due to factors such as rapid technological advances or changes in customers' taste (Sharfman \& Dean 1991). Dynamism primarily reflected instability (volatility) (Keats \& Hitt 1988). Organizations operate in such dynamic environment is more likely to face difficulty to predict the availability of environmental resources in the future. The second dimension measures the munificence of resources in the environment that depends on supply and demand of the same resources. Poor environment resulting form exhausted supply, new entries, and/ or dominant competitors poses a threat to the organization's ability to protect and expand its domain and thereby, dampening growth (Jones 2001). The last dimension is concentration that measures the degree to which a few firms control industry sales. Thus, concen- 
tration protects large firms from the possibility of new entrants (cited in Weinzimmer \& Nystrom 1998).

Firms operating in complex environment should benefit from the functional flexibility. When there are fewer potential competitors, the environment is less complex, and therefore less need for TMT heterogeneity (Richard \& Shelor 2002). They further argued that TMT heterogeneity is better for uncertain environments, while TMT homogeneity appears more beneficial in stable environments. Supporting this argument, Richard and Shelor (2002) confirmed that environmental complexity moderates the relationship between TMT age heterogeneity and firm performance.

Using this rationale, I expect the breadth of perspective and creativity obtained from TMT tenure and heterogeneity to relate positively to organizational growth for firms operating in complex environments. When the TMT heterogeneity is high, the members may interpret and experience the diversity of opinions and views. Heterogeneity in decisions and problem solving contributes better decisions through providing a wider range of perspectives and more thorough critical analysis of issues (Richard \& Shelor 2002). In contrast, when TMT heterogeneity is low, team members will unlikely to set creative ideas and to adopt less changes in corporate strategy, which may be pertinent in a complex environment.

As an environment grows more turbulent (uncertain or complex), and a firm's decision-making tasks grow more difficult, managers have greater information-processing requirements (Haleblian \& Finkelstein 1993). In much the same way that the environment turbulence moderates the relationship between top team size and firm performance (Haleblian \& Finkelstein 1993), the organization's environment moderates the association between top management attributes and organizational growth. Hence, I would expect organizational growth to be positively associated with top management attributes in more complex environments.

H4 : Environment (dynamism, munificence and concentration) positively moderates the relationship between TMT tenure and organizational growth.

Figure 1 exhibits a model of relationships between TMT attributes and organizational growth, and environment dimensions (moderating), either individually or jointly. 
Figure 1: Conceptual framework of the TMT attributes-environment dimensions (moderator)organizational growth relationships

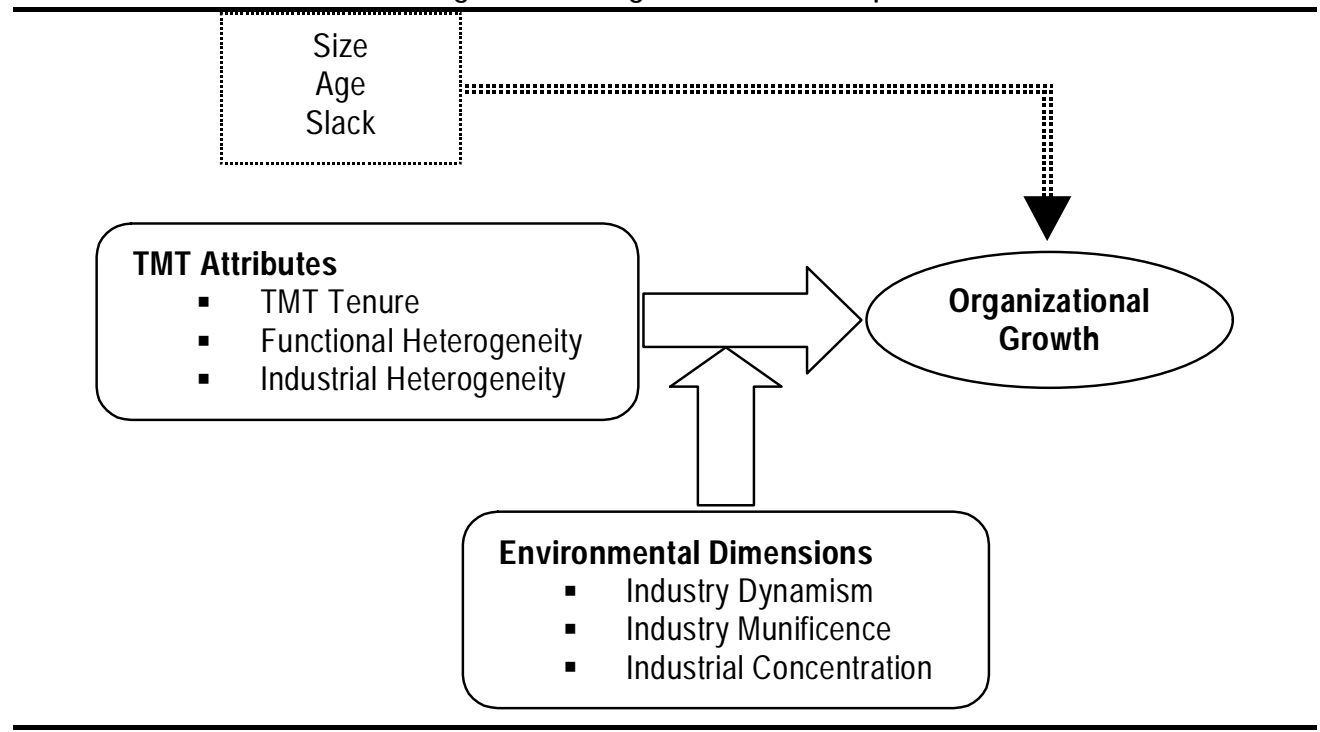

Note: TMT = Top Management Team. The three variables in the dotted box are control variables.

H5 : Environment (dynamism, munificence and concentration) positively moderates the relationship between TMT functional heterogeneity and organizational growth.

H6 : Environment (dynamism, munificence and concentration) positively moderates the relationship between TMT industrial heterogeneity and organizational growth.

\section{METHODOLOGY}

\section{Sample}

The sample of this study consists of three industries: (1) Construction; (2) Trading/Services; and (3) Services. They are selected in order to neutralize the bias effect of any particular concept used in this study, and because of these choices, however, the results may have limited generalizability. The sample is purposefully selected according to two criteria: (1) the organization is continuously listed on the Kuala Lumpur Stock Exchange (KLSE) Main Board for 5-year period starting 1998 until 2002; and (2) the organization must be one that provides complete information on their directors. The complete information about the TMTs directors from 73 companies are managed to gather, and thus, decide to examine the impact of TMTs directors attributes on organizational performance. Of these 73 companies: 29 are from Industrial, Trading/Services are 32, and while Con- 
struction consists of 12 companies. Company account data for the 5-year study period (1998 to 2002) are collected from Data stream. Meanwhile, data on the company's TMTs directors are collected from each company's website, annual reports, and the Kuala Lumpur Stock Exchange's online databases. Due to the availability of the data, this study utilizes only the annual data, contrary to Weizimmer et al. (1998) suggestion that quarterly company account data would be more appropriate.

\section{Dependent Variable}

Organizational Growth. Organizational growth, the dependent variable, is defined as a relative measure of size over time (Weinzimmer et al. 1998). In Weinzimmer et al. (1998), there are three alternative concepts of size and formulas of organizational growth. For the purpose of this study, I only adopt the operational definitions of average asset growth. Following Weinzimmer et al. (1998) again, the average growth measure is represented in Eq. 1:

$$
A A G_{J}=\frac{S_{E j}-S_{B j}}{n}
$$

where $A A G_{j}=$ the average assets growth, $S_{E j}$ and $S_{B j}=$ size of the $j$ th firm at the Beginning or Ending of the study period, respectively, and $\mathrm{n}$ is five consecutive years from 1998 to 2002. Size is defined as the log of actual inflation-adjusted sales, inflation-adjusted assets, or number of employees.

\section{Independent Variables}

TMTs Directorial Attributes. Weinzimmer et al. (1998) suggest six attributes of TMT to explain organizational growth: (1) industry heterogeneity of TMT; (2) functional heterogeneity of TMT; (3) TMT size; (4) TMT organizational tenure; (5) TMT age; and (6) TMT membership in the Board of Directors. For the purpose of the study, only three TMTs attributes will be tested, such (1) TMT functional heterogeneity; (2) TMT industrial heterogeneity; and (30 TMT tenure. The operationalization used in prior TMT studies (e.g., Murray 1989; Michel \& Hambrick, 1992), yields a more complete group than if only executives who are inside directors are included (e.g., Finkelstein \& Hambrick 1990).

The chosen operationalization is intended to include all major line and staff executives, encompassing all the key activities of the firm at the senior-most level. Each of these three types of TMT attributes has been used in prior studies, but typically not together. The three types are complementary, reflecting diversity on somewhat different dimensions. To the extent that results are consistent across the three types, I can have greater confidence in the effects of TMT attributes on organizational growth. 
Functional heterogeneity of the directors is measured by the number of functional disciplines represented by the BOD members divided by the size of the TMT. Following Weinzimmer et al. (1998) and Michel and Hambrick (1992) in using Herfindal-Hirshman index to measure this variable:

$H=1-\sum_{i=1}^{9}\left(S_{i}\right)^{2}$

where $\mathrm{H}$ is functional heterogeneity of the directors and $\mathrm{S}_{i}$ is the percentage of a director's time spent on career track $i$ than any other . In these earlier studies, variable $i$ is coded using a 9-point scale consisting of the following functional categories: production operations, R\&D, finance, accounting, general management, marketing, law, administration, and human resource. A lower score in a range of 0 to 1 indicates homogenous directors with only one or two dominant functional areas. Furthermore, directors' industrial heterogeneity is the variance in the industry experience of the directors, measured as the coefficient of variation of the number of different industries the BOD members are involved with.

Several alternative measures of managerial tenure are considered, including tenure in position, tenure in the TMT, and tenure in the industry. For the purpose of this study, TMT organizational tenure is measured as the mean number of employment in years that the board members had been with the organization. Tenure in the firm is adopted here because this tenure variable most highly correlated with other tenure measures, hence serving as a central, parsimonious indicator of the broad concept of tenure.

\section{Moderator Variables}

Environmental Dimensions. The three environmental dimensions (dynamism, munificence and concentration) are used as moderator variables in this study. The environmental complexity is measured with industry concentration (Romanelli 1989; Eisenhardt \& Schoonhoven 1990; Weinzimmer et al. 1998), which recognizes the influence of the competitors on the difficulty to access environmental resources. Defined as the degree to which competitors are already in control of critical resources (Romanelli 1989), industry concentration or competitive concentration is operationalized by taking the average of percentage changes in 4-firm unit sales concentration ratio (Eisenhardt \& Schoonhoven 1990; Romanelli 1989). Following Romanelli, concentration is;

$$
\operatorname{CON}_{k}=\frac{1}{N} \sum_{t=1}^{N}\left(\frac{S_{K, t+1}-S_{K, t}}{S_{K, t}} \times 100 \%\right)
$$

where $S_{K, t}$ is the total sales of the 4 largest companies in the $k$ th industry at the th period. 
Industry dynamism and stability is measured as by industry dynamism (Dess \& Beard 1984; Weinzimmer et al. 1998) which is estimated as follows;

$$
D Y N_{k}=\frac{\sigma_{\beta 1 k}}{\mu_{Y k}}
$$

where $\sigma_{\beta 1 \mathrm{k}}$ is the standard error of the regression coefficient for the munificence standardized for size of the industry by $\mu_{\gamma k}$, i.e. the mean sales of the $k$ th industry.

Finally resource availability is measured by environmental munificence (Dess \& Beard 1984, Weinzimmer et al. 1998). Following Weinzimmer et al. (1998), munificence is the industry growth that is the inflationadjusted changes in the overall industry sales (Boeker 1997) obtained by adjusting beta coefficient from regressing industry-level sales (Dess \& Beard 1984; Weinzimmer et al. 1998) over time. It is similar to the organizational growth in Eq. 1 with size takes the value of total sales of all firms in the respective industry.

\section{Control Variables}

Organizational slack, firm age, and firm size are controlled for in this study because of their likely effect on organizational effectiveness. These control variables are those identified as most essential in the TMT and organizational growth literatures. Organizational slack is measured as the ratio of assets to debt (Eisenhardt \& Schoonhoven 1990; Weinzimmer et al. 1998). Firm age is the duration from the date the firm is incorporated until the beginning of this study period of 1998 in years (Weinzimmer et al. 1998). Firm size is the logarithm of total assets averaged for the 5-year study period (Michel \& Hambrick 1992; Weinzimmer et al. 1998).

\section{Procedure}

Hierarchical regression analysis is used to test the hypotheses and assesses the changes in $\mathrm{R}^{2}$ after each stage. The order of entry is: (Model 1) control variables; (Model 2) adds the direct effect of TMT tenure; (Model 3) adds the direct effects of three moderator variables of environmental dimensions (munificence, dynamism and concentration); and finally, (Model 4) includes the interactions between TMT attributes (TMT tenure, TMT functional heterogeneity and TMT industrial heterogeneity) and environmental dimensions (moderator variables) on organizational growth. 


\section{RESULTS AND DISCUSSIONS}

Table 1 provides means, standard deviation and correlations for all variables. All of the variables show positive relationships towards organizational growth except for firm size and firm slack show negative relationships. These results are parallel with the hypotheses and past literatures.

Table 1: Descriptive Statistics and Correlations for All Variables ( $N=73)$

\begin{tabular}{|c|c|c|c|c|c|c|c|c|c|c|c|}
\hline & Mean & Std. Dev. & 1 & 2 & 3 & 4 & 5 & 6 & 7 & 8 & 9 \\
\hline 1. Org. rowth & 0.02 & 0.06 & & & & & & & & & \\
\hline 2. Firm Size & 0.01 & 0.05 & $.85^{\star \star}$ & & & & & & & & \\
\hline 3. Firm Slack & 2533.21 & 15123.77 & -0.07 & -0.04 & & & & & & & \\
\hline 4. Firm Age & 22.30 & 12.35 & -0.14 & -0.07 & 0.05 & & & & & & \\
\hline $\begin{array}{l}\text { 5. TMT Tenure } \\
\text { 6. TMT }\end{array}$ & 7.16 & 4.14 & 0.22 & 0.14 & -0.14 & $.38 * \star$ & & & & & \\
\hline Functional & & & & & & & & & & & \\
\hline $\begin{array}{l}\text { Heterogeneity } \\
\text { 7. TMT } \\
\text { Industrial }\end{array}$ & 0.49 & 0.23 & 0.07 & 0.07 & 0.07 & 0.07 & 0.07 & & & & \\
\hline $\begin{array}{l}\text { Heterogeneity } \\
\text { 8. Environmental }\end{array}$ & 1.88 & 1.72 & $.29^{\star}$ & $.27^{\star}$ & -0.07 & -0.06 & 0.22 & -0.13 & & & \\
\hline $\begin{array}{l}\text { Concentration } \\
\text { 9. Environmental }\end{array}$ & 16.15 & 18.83 & 0.23 & 0.18 & $.4^{\star \star}$ & $-.32^{\star *}$ & -0.02 & 0.01 & 0.21 & & \\
\hline $\begin{array}{l}\text { Dynamism } \\
\text { 10. Environmental }\end{array}$ & 10.95 & 12.90 & 0.22 & 0.18 & $.44^{\star *}$ & $-.29 *$ & -0.01 & 0.02 & 0.20 & $.99 * *$ & \\
\hline Munificence & 10.29 & 11.68 & 0.09 & 0.03 & $.63^{\star *}$ & -0.21 & -0.03 & 0.01 & 0.15 & $.92^{\star \star}$ & $.94^{\star *}$ \\
\hline
\end{tabular}

Note: * and ** indicate significant at 0.05 and 0.01 level, respectively 
Table 2: Hierarchical Regression: Results of Interaction between Top Management Team Tenure and Environment on Organizational Growth

\begin{tabular}{|c|c|c|c|c|}
\hline Variables & Model 1 & Model 2 & Model 3 & Model 4 \\
\hline Intercept & 0.02 & 0.02 & -0.01 & -0.02 \\
\hline Firm Size & $0.96^{\star \star \star}$ & $0.93^{\star \star \star}$ & $1.03^{\star \star \star}$ & $1.05^{\star \star \star}$ \\
\hline Firm Slack & 0.00 & 0.00 & 0.00 & 0.00 \\
\hline Firm Age & 0.00 & $0.01^{*}$ & 0.00 & 0.00 \\
\hline TMT Tenure & & $0.02^{\star}$ & $0.01^{*}$ & $0.03^{*}$ \\
\hline Environmental Concentration & & & $.02^{*}$ & 0.08 \\
\hline Environmental Dynamism & & & $-0.03^{*}$ & -0.02 \\
\hline Environmental Munificence & & & $0.04^{\star}$ & $0.01 * \star \star$ \\
\hline $\begin{array}{l}\text { TMT Tenure } X \\
\text { Environmental Concentration }\end{array}$ & & & & -0.01 \\
\hline $\begin{array}{l}\text { TMT Tenure X } \\
\text { Environmental Dynamism }\end{array}$ & & & & 0.02 \\
\hline $\begin{array}{l}\text { TMT Tenure X } \\
\text { Environmental Munificence }\end{array}$ & & & & 0.00 \\
\hline Change in $\mathrm{R}^{2}$ & 0.725 & 0.021 & 0.027 & 0.054 \\
\hline $\mathrm{R}^{2}$ & 0.725 & 0.745 & 0.773 & 0.826 \\
\hline F-statistic Change & $60.557^{\star \star *}$ & $5.518 *$ & $2.599 *$ & $6.408^{\star *}$ \\
\hline Df & 3,69 & 1,68 & 3,65 & 3,62 \\
\hline
\end{tabular}

Note: ${ }^{*},{ }^{* \star}$ and ${ }^{* \star *}$ indicate significant at $0.05,0.01$ and 0.001 level, respectively.

In Table 2, the effects of the environment and TMT tenure on organizational growth are presented in four models. The first model includes only the control variables; 0 the second model adds the direct effect of TMT tenure; the third model adds the direct effects of three variables of environment (munificence, concentration \& dynamism); the forth model includes the interactions between TMT attributes (TMT tenure, TMT functional heterogeneity and TMT industrial heterogeneity) and environmental dimensions. The three control variables were entered in the first model of Table 2. They explained $72.5 \%$ of the variance in organizational growth. Hypothesis 1 predicts that organizational growth will exhibit a positive relationship with TMT tenure. Result of this main effect in model 2 shows a significant positive relationship. Model 3 also shows that all of the environment dimensions affect organizational growth significantly. The final model examines the interactive effects of TMT tenure and environment dimensions individually. Hypothesis 4 predicts that environment moderates the relationship between TMT tenure and organizational growth. As can be seen in model 4 of Table 2 , this hypothesis is supported for munificence but not for dynamism and concentration. The power of the model improves modestly $\left(\Delta \mathrm{R}^{2}=5.6 \%\right)$. The partial F-test shows that Model 4 is significantly different from Model 3 
at $p<0.01$. Thus, the results support the prediction of an interactive effect between TMT tenure and munificence on organizational growth such that, as munificence increases, the relationship between TMT tenure and organizational growth shows increasingly positive.

Table 3: Hierarchical Regression Results of Interaction between Top Management Team Functional Heterogeneity and Environment on Organizational Growth

\begin{tabular}{|c|c|c|c|c|}
\hline Variables & Model 1 & Model 2 & Model 3 & Model 4 \\
\hline Intercept & $0.02^{\star \star}$ & $0.02^{*}$ & -0.01 & -0.01 \\
\hline Firm Size & $0.97^{\star \star \star *}$ & $0.96^{\star \star *}$ & $1.06^{\star \star *}$ & $1.19 * \star \star$ \\
\hline Firm Slack & 0.00 & 0.00 & 0.00 & 0.00 \\
\hline Firm Age & 0.00 & 0.00 & 0.00 & 0.00 \\
\hline TMT Functional Heterogeneity & & 0.01 & 0.02 & 0.03 \\
\hline Environmental Concentration & & & $0.02^{*}$ & $0.03^{\star *}$ \\
\hline Environmental Dynamism & & & $-0.003^{*}$ & $-0.05^{\star *}$ \\
\hline Environmental Munificence & & & $0.01 *$ & $0.01^{\star *}$ \\
\hline $\begin{array}{l}\text { TMT Functional Hetero. X } \\
\text { Environmental Concentration }\end{array}$ & & & & $-0.05^{\star}$ \\
\hline $\begin{array}{l}\text { TMT Functional Hetero. X } \\
\text { Environmental Dynamism }\end{array}$ & & & & $0.09 *$ \\
\hline $\begin{array}{l}\text { TMT Functional Hetero. X } \\
\text { Environmental Munificence }\end{array}$ & & & & $-0.02^{*}$ \\
\hline Change in $\mathrm{R}^{2}$ & 0.725 & 0.000 & 0.029 & 0.030 \\
\hline $\mathrm{R}^{2}$ & 0.725 & 0.709 & 0.727 & 0.749 \\
\hline F-statistic Change & $60.56^{\star \star \star}$ & 0.05 & 2.51 & $2.91^{*}$ \\
\hline$d f$ & 3,69 & 1,68 & 3,65 & 3,62 \\
\hline
\end{tabular}

Note: *, ${ }^{* \star}$ and ${ }^{* \star *}$ indicate significant at $0.05,0.01$ and 0.001 level, respectively.

The results for hypothesis $2 \mathrm{a}$ are found in Table 3 (model 2 ). Similar to Table 2, the hierarchical regression is performed using four steps. The results show that when controlling for size, slack and firm age, TMT functional heterogeneity is insignificant with no change in the variance of the dependent variable. Thus, hypothesis $2 \mathrm{a}$ is not supported. However, when environment dimensions are entered into model 3 , all of the environment dimensions show strong relationships toward organizational growth. Hypothesis 5 dealt with the interaction effect of TMT functional heterogeneity and environment dimensions on organizational growth. Later, when the two interaction terms are entered in step 4, the power of the model increases slightly $\left(\Delta \mathrm{R}^{2}=3 \%\right)$. Model 4 supports hypothesis 5 , which is significant at the 0.05 level. Examination of the interaction effects revealed that concentration, dynamism and munificence moderate the relationship between TMT functional heterogeneity and organizational growth. 
Table 4 examines Hypothesis $2 \mathrm{~b}$ and 4 . Similar to Table 2, four steps of hierarchical regressions are performed. As hypothesized, Model 2 shows that there is a positive relationship between TMT industrial heterogeneity on organizational growth. However, this direct effect is insignificant to the model. Thus, Hypothesis $2 \mathrm{~b}$ is not supported. Model 3 shows that all of three environment dimensions are significant (at $\alpha=0.05$ ). Next, in Model 4, the results support the prediction of interactive effects between TMT heterogeneity and environment dimensions on organizational growth. The change in $\mathrm{R}^{2}$ is $3 \%$ (significant at $\alpha=0.05$ ). For the first interaction, as environment concentration increases, the relationship between TMT industrial heterogeneity and organizational growth increases positively. In contrast, the second interaction shows that as environment dynamism increases, the relationship between TMT industrial heterogeneity and organizational growth increases negatively. Further, the last interaction between TMT industrial heterogeneity and environment munificence is not significant to explain the organizational growth.

Table 4:Hierarchical Regression Results of Interaction between Top Management Team Industrial Heterogeneity and Environment on Organizational Growth

\begin{tabular}{|c|c|c|c|c|}
\hline Variables & Model 1 & Model 2 & Model 3 & Model 4 \\
\hline Intercept & $0.03^{\star \star}$ & $0.02^{*}$ & 0.01 & -0.01 \\
\hline Firm Size & $0.97^{\star \star \star}$ & $0.95^{\star \star \star}$ & $1.05^{\star \star \star}$ & $1.04^{\star \star \star}$ \\
\hline Firm Slack & 0.00 & 0.00 & 0.00 & 0.00 \\
\hline Firm Age & 0.00 & 0.00 & 0.00 & 0.00 \\
\hline TMT Industrial Heterogeneity & & 0.01 & 0.01 & 0.01 \\
\hline Environmental Concentration & & & $0.01^{*}$ & 0.01 \\
\hline Environmental Dynamism & & & $-0.02^{*}$ & $-0.02^{*}$ \\
\hline Environmental Munificence & & & $0.01^{*}$ & $0.01^{* *}$ \\
\hline $\begin{array}{l}\text { TMT Industrial Hetero. X } \\
\text { Environmental Concentration }\end{array}$ & & & & $0.01^{*}$ \\
\hline $\begin{array}{l}\text { TMT Industrial Hetero. X } \\
\text { Environmental Dynamism }\end{array}$ & & & & $-0.01^{*}$ \\
\hline $\begin{array}{l}\text { TMT Industrial Hetero. X } \\
\text { Environmental Munificence }\end{array}$ & & & & -0.01 \\
\hline Change in $\mathrm{R}^{2}$ & 0.725 & 0.01 & 0.03 & 0.03 \\
\hline $\mathrm{R}^{2}$ & 0.725 & 0.728 & 0.752 & 0.774 \\
\hline F-statistic Change & $60.58 * \star \star$ & 0.91 & 2.02 & $3.12^{\star}$ \\
\hline Df & 3,69 & 1,68 & 3,65 & 3,62 \\
\hline
\end{tabular}

Note: * ${ }^{* \star}$ and ${ }^{* \star \star}$ indicate significant at $0.05,0.01$ and 0.001 level, respectively. 


\section{CONCLUSIONS AND IMPLICATIONS}

The hypotheses that have been empirically tested in this study representing somewhat different conceptualizations of the relations among TMTs directorial attributes, environmental dimensions and organizational growth. The hypotheses incorporate elements of existing theoretical perspectives and are based on different setting than prior studies. The limitation of this study is difficult to ascertain generalization of the relationships among variables tested, as it is obviously that data collection are obtained from limited organizations, a certain number of industry and at a particular of time. However, the overall results provide mixed effects for the hypotheses tested of TMTs directorial attributes, environmental dimensions and organizational growth.

The results allow conclusions at third levels. First, it is appear that result of main effect shows that organizational growth exhibits a significant positive relationship with TMT tenure. The results also support the prediction of an interactive effect between TMT tenure and munificence on organizational growth such that, as munificence increases, the relationship between TMT tenure and organizational growth shows increasingly positive.

At second level, the results indicate that when controlling for size, slack and firm age, TMT functional heterogeneity is insignificant with no change in the variance of the dependent variable. Thus, hypothesis $2 a$ is not supported. However, when environment dimensions are entered into model 3, all of the environment dimensions show strong relationships toward organizational growth. Examination of the interaction effects revealed that concentration, dynamism and munificence moderate the relationship between TMT functional heterogeneity and organizational growth.

The third level results show that there is a positive relationship between TMT industrial heterogeneity on organizational growth. However, this direct effect is insignificant to the model. However, the interaction effects provide mixed results: (1) as environment concentration increases, the relationship between TMT industrial heterogeneity and organizational growth increases positively; (2) by contrast, as environment dynamism increases, the relationship between TMT industrial heterogeneity and organizational growth increases negatively; (3) finally, the interaction between TMT industrial heterogeneity and environment munificence is not significant to explain the organizational growth.

To conclude, this study hopefully will direct towards more refined empirical research of TMTs attributes, environmental dimensions and organizational growth. There is clearly opportunity for further research to investigate on other dimensions or curvilinear relationships among these variables. 


\section{REFERENCES}

Bantel, K \& Jackson, S. 1989. Top management and innovations in banking: does the composition of the top team make a difference? Strategic Management Journal, 10: 107-124.

Boeker, W. 1997. Strategic change: the influence of managerial characteristic and organizational growth. Academy of Management Journal 40(1): 152-170.

Dess, G.G. 1987. Consensus on strategy formulation and organizational performance: competitors in a fragmented industry. Strategic Management Journal 8(3): 259-277.

, \& Origer N.K. 1987. Environment, structure, and consensus in strategy formulation: a conceptual integration. Academy of Management Review 12(2): 313-330.

, \& Rasheed, A.M.A. 1991. Conceptualizing and measuring organizational environments: a critique and suggestions. Journal of Management 14(4): 701-710.

Eisenhardt, K.M. and Schoonhoven, C.B. 1990. Organizational growth: linking the founding team, strategy, environment and growth among U.S. semiconductor ventures, 1978-1988. Administrative Science Quarterly 35 (3): 504-529.

Finkelstein, S. and Hambrick, D.C. 1990. Top-management-team tenure and organizational outcome: the moderating role of managerial discretion. Administrative Science Quarterly, 35(3):

Haleblian, J. and Finkelstein, S. 1993. Top management team size, CEO dominance, and firm performance: the moderating roles of environmental turbulence and discretion. Academy of Management Journal, 36(4): 844-863

Hambrick, D.C. \& Mason P.A. 1984. Upper echelons: the organization as a reflection of its top managers. Academy of Management Review 9(2): 193-206.

, \& Cho, T. 1996. The influence of top management team heterogeneity on firms' competitive moves. Administrative Science Quarterly, 41(4): 659-685

Hamilton, R.T. \& Shergill, G.S. 1992. The relationship between strategystructure fit and financial performance in New Zealand: evidence 
of generality and validity with enhanced controls. Journal of Management Studies, 29: 95-113.

Hubbard, G. \& Bromiley, P. 1995. Researchers and top managers: how do they measure firm performance? In Weinzimmer, L.G, Nystorm, P.C., and Freeman, S.J. 1998. Measuring organizational growth: issues, consequences and guidelines. Journal of Management 24(2): 235-262.

Jackson, S.E. 1992. Consequences of group composition for the interpersonal dynamics of strategic issue processing. In P. Shrivastava, A.H. \& Dutton, J. (eds.). Advances in Strategic Management, 8: 345-382

Johnson, G. \& Thomas, H. 1987. The industry context of strategy, structure, and performance: the U.K. brewing industry. Strategic Management Journal, 8: 343-361.

Jones, G.R. 2001. Organizational theory: text and cases. Third Edition. Prentice Hall Inc. New Jersey.

Keats, B.W. and Hitt, M.A. 1988. A causal model of linkages among environmental dimensions, macro-organizational characteristic, and performance. Academy of Management Journal, 31(3): 570-598.

Keck, S.L. 1997. Top management team structure: differential effects by environmental context. Organizations Science, 8(2): 143-156

Marino, K.E. and Lange, D.R. 1983. Measuring organizational slack: a note on the convergence and divergence of alternative operational definitions. Journal of Management, 9(1): 81-92

Michel, J.G. and Hambrick, D.C. 1992. Diversification posture and top management team characteristics. Academy of Management Journal 35(1): 9-37.

Michie, S.G., Dooley, R.S. \& Fryxell, G.E. 2002. Top management team heterogeneity, consensus, and collaboration: a moderated mediation model of decision quality. Academy of Management Proceedings: $1-6$

Mileti, D.S., Gillespie, D.F., \& Haas, J.E.1977. Size and structure in complex organizations. Social Forces 56(1): 208-217.

Miller, D. 1991. Environmental fit versus internal fit. Organization Science 3(2): 159-178. 
Murray, A.I. 1989. Top management group heterogeneity and firm performance. Strategic Management Journal, 10:125-41

Neilsen, E.H. 1978.The human side of growth. Organizational Dynamics: 61-80.

Priem, R.L. 1990. Top management team group factors, consensus, and firm performance. Strategic Management Journal 11(6): 469-478.

Priem, R.L., Lyon, D.W. \& Dess, G.G. 1999. Inherent limitations of demographic proxies in top management team heterogeneity research. Journal of Management, 25(6): 935-953

Richard, O.C. and Shelor, R.M. 2002. Linking top management team age heterogeneity to firm performance: juxtaposing two mid-range theories. The International Journal of Human Resources Management 13(6): 958-974.

Romanelli, E. 1989. Environments and strategies of organization start-up: effects on early survival. Administrative Science Quarterly 34(3): 369-387.

Robbins, S.P. 1990. Organization Theory: structure, design, and applications. Third Edition. Prentice Hall International Inc., London.

Sharfman, M.P. and Dean, J.W.Jr. 1991. Conceptualizing and measuring the organizational environment: a multidimensional approach. Journal of Management 17(4): 681-700.

1991. Dimensions and constructs: a response to Dess and Rasheed. Journal of Management 17(4): 711-715.

Weinzimmer, L.G. 1997 (July). Top management team correlates of organizational growth in a small business context: a comparative study. Journal of Small Business, 35(3): 1-9.

2000. A replication and extension of organizational growth determinants. Journal of Business Research, 48(1): 35-41

, Nystorm, P.C., and Freeman, S.J. 1998. Measuring organizational growth: issues, consequences and guidelines. Journal of Management 24(2): 235-262. 